\title{
Parotiditis aguda en recién nacido
}

\section{Neonatal acute parotitis}

Rodrigo Cabezón $\mathrm{A}^{1}$, Javiera Kreft $\mathrm{V}^{2}$, Constanza Ramírez $\mathrm{R}^{3}$, Daniela Witker $\mathrm{J}^{3}$.

\section{RESUMEN}

La parotiditis aguda supurativa es una enfermedad extremadamente infrecuente en el recién nacido, sin casos publicados hasta ahora en la literatura nacional y con pocos casos descritos en la literatura médica mundial. La infección ocurre habitualmente por vía ascendente desde la cavidad oral al conducto de Stenon, o asociado a sialectasia, aunque también se ha descrito a la deshidratación y la septicemia con extensión hacia la glándula parótida como probables mecanismos patogénicos.

Se presenta el caso de un neonato de 13 días, sin antecedentes perinatales de relevancia, del Hospital Roberto del Río, que presenta cuadro de 12 horas de evolución caracterizado por irritabilidad, fiebre, aumento de volumen parotídeo derecho, doloroso, eritematoso y salida de pus por el conducto de Stenon. Se realiza diagnóstico clínico, microbiológico e imagenológico, con aislamiento de Staphylococcus aureus multisensible de la secreción parotídea. Se inicia tratamiento con cefotaximo y cloxacilina, con respuesta favorable. A partir del presente caso realizamos una revisión bibliográfica, para discutir el enfoque diagnóstico, terapéutico y pronóstico de esta patología.

Palabras clave: parotiditis supurativa, neonatal, Staphylococcus aureus.

\begin{abstract}
Neonatal acute suppurative parotitis is an extremely uncommon disease in newborns, without any published cases in national literature. Thought ascending infection from oral cavity to Stenon's duct and sialectasia are most common pathological mechanisms, dehydration and septicaemia with parotid extension has been proposed as other potential pathways.

We present a 13 days neonate, without perinatal history, from Roberto del Río Pediatric Hospital, presenting 12 hours of fever, pain, irritability, right parotid swelling and purulent secretion from right Stenon's duct. Clinical, microbiological and radiological diagnosis was made, isolating multisensible Staphyloccus aureus from secretion cultures. Antibiotical treatment (cefotaxime plus cloxaciline) was initiated, with a successful course. From this case, we reviewed literature for further discussion of diagnostic, therapeutic and prognosis of this disease.
\end{abstract}

Key words: suppurative parotitis, neonatal, Staphylococcus aureus.

\footnotetext{
Médico del Departamento de Otorrinolaringología, Hospital Clínico Pontificia Universidad Católica de Chile.

2 Médico Pediatra. Departamento de Pediatría y Cirugía Infantil Hospital Roberto del Río. Facultad de Medicina. Universidad de Chile.

3 Interna Medicina Universidad de Chile.
} 


\section{INTRODUCCIÓN}

La parotiditis aguda supurativa es una enfermedad extremadamente infrecuente en el recién nacido. En los últimas 3 décadas se han reportado tan solo 32 casos en la literatura mundial ${ }^{1}$, sin casos publicados en la literatura nacional. Se han descrito como factores predisponentes la prematuridad, la baja de peso, la deshidratación o la nutrición con sonda orogástrica ${ }^{2,3}$. Otro mecanismo patogénico descrito es la septicemia con extensión hacia la glándula parótida ${ }^{4}$.

A pesar de ser una patología poco frecuente su diagnóstico y tratamiento tardío puede ser letal 5 . A continuación se presenta el caso de un neonato de 13 días, que consulta en el Hospital Roberto del Río con cuadro de aumento de volumen cervical derecho, fiebre y salida de pus por conducto de Stenon.

\section{CASO CLÍNICO}

Paciente recién nacido varón, segundo gemelar dicigótico. Madre de 28 años sana, sin antecedentes mórbidos. Segundo embarazo controlado, sin patologías.

Parto por cesárea por distocia de posición (podálica segundo gemelar), sin trabajo de parto, a las $37^{+5}$ semanas de gestación. Peso al nacimiento $3.230 \mathrm{gr}$. Sin anormalidades perinatales o posnatales.

Se le realiza un control médico a la semana de vida sin anormalidades y con buen incremento ponderal. Alimentación con lactancia materna desde nacimiento más suplemento ocasional.

A los 13 días de vida en su domicilio presenta cuadro de aproximadamente 12 horas de evolución caracterizado por irritabilidad y aumento de volumen en región mandibular derecha.

Es traído al Servicio de Urgencia del Hospital Roberto del Río donde se constata fiebre $\left(38^{\circ} \mathrm{C}\right.$ axilar) y aumento de volumen mandibular derecho (Figura 1) por lo que se decide su hospitalización.

Al examen físico se encuentra reactivo, en buenas condiciones generales, febril. Resto de los parámetros hemodinámicos normales: presión arterial $87 / 33 \mathrm{mmHg}$, frecuencia respiratoria 48 $\mathrm{resp} / \mathrm{min}$, frecuencia cardiaca $156 \mathrm{lat} / \mathrm{min}$ y saturación de oxígeno $96 \%$.

Al examen dirigido destaca un aumento de volumen de $3 \times 5 \mathrm{cms}$ en la región parotídea derecha, indurado, doloroso a la palpación, eritematoso y con calor local. Se objetiva salida de secreción purulenta por conducto de Stenon al presionar la glándula parótida derecha. No presenta adenopatías cervicales palpables.

El resto de la exploración segmentaria sin anormalidades.

Se solicita un perfil hematológico (cell-dyn) con un recuento de 20.500 leucocitos (neutrófilos $71,3 \%$, linfocitos 16,6\%, monocitos 9,5\%), hemoglobina de $13,8 \mathrm{gr} / \mathrm{dl}$, hematocrito de $40,2 \%$, plaquetas de 382.000 y PCR de 13,3. El hemocultivo resulta negativo.

La tinción Gram de la secreción del conducto de Stenon muestra leucocitos y células epiteliales en escasa cantidad y abundantes cocáceas Gram positivas.

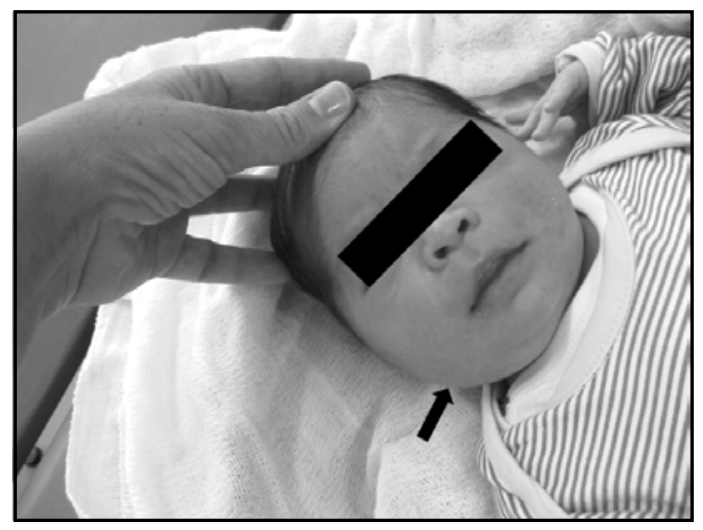

Figura 1. Fotografía del paciente mostrando aumento de volumen de la región parotídea derecha. 
El cultivo de la secreción parotídea resulta positivo para $S$. aureus en dos muestras; con un antibiograma multisensible. Sedimento de orina normal. Urocultivo negativo. Se realiza una punción lumbar con citoquímico y citológico normales. Cultivo de LCR negativo.

El estudio ecográfico visualiza un aumento de espesor y disminución de la ecogenicidad de la glándula parótida derecha con aumento de la vascularización al estudio Doppler color, sin lesiones focales; junto con un aumento del espesor y ecogenicidad de la piel y tejido subcutáneo adyacente a esta glándula. La glándula parótida izquierda, tiroides y submandibular no evidencian

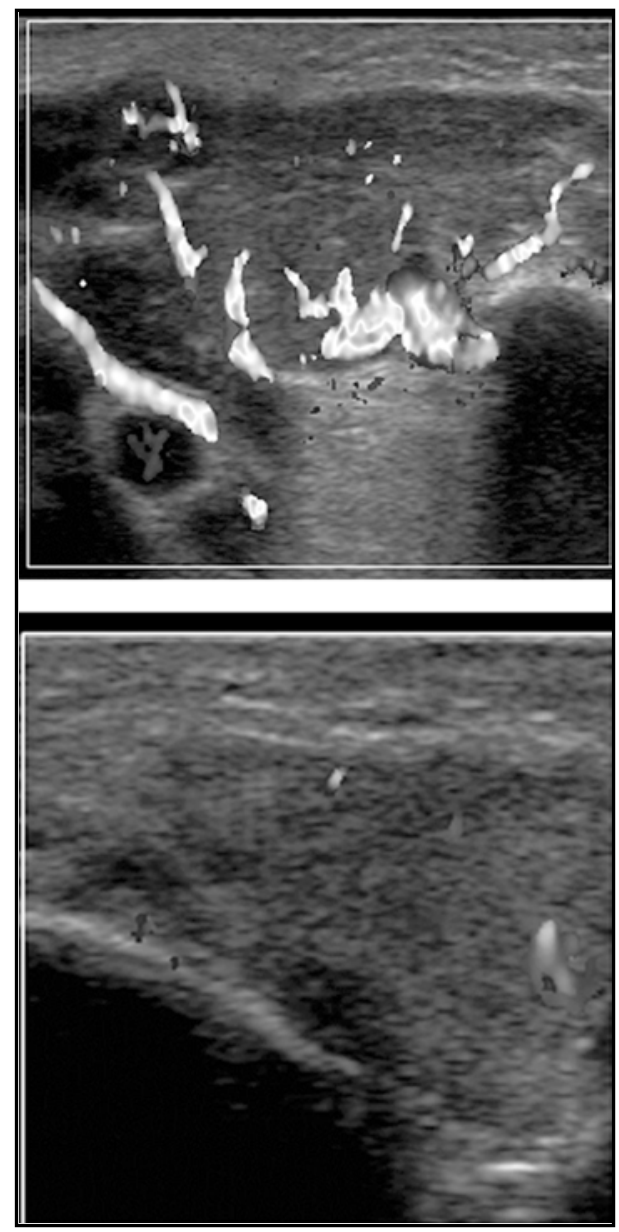

Figura 2. Ecografía con doppler del mismo paciente en la que se visualiza glándula parótida derecha aumentada de tamaño, hipoecogénica y con aumento de su vascularización. alteraciones. Presencia de algunos linfonodos cervicales de tamaño dentro de lo normal. Se informa que los hallazgos eran concordantes con el diagnóstico clínico de parotiditis aguda derecha (Figura 2).

Se indica tratamiento antibiótico empírico EV con cefotaxima y cloxacilina para cubrir gérmenes del canal de parto y $S$. aureus. A las $48 \mathrm{hrs}$ de tratamiento en respuesta al cultivo positivo para $S$. aureus y hemocultivo negativo, se ajusta el tratamiento antibiótico manteniendo sólo la cloxacilina EV.

El recién nacido evoluciona satisfactoriamente al tratamiento antibiótico con evidente disminución del volumen mandibular derecho, no presenta nuevamente secreción a través del conducto de Stenon. Se sustituye cloxacilina EV por flucloxacilina oral para completar tratamiento en forma ambulatoria. En total se completaron 48 hrs con cefotaxima y 3 días con cloxacilina endovenosa.

Por buen estado general y favorable respuesta a antibióticos se decide alta con indicación de flucloxacilina por 7 días, y control en una semana en forma ambulatoria.

Al control se encuentra afebril, en buenas condiciones generales, con remisión completa de la induración parotídea (Figura 3).

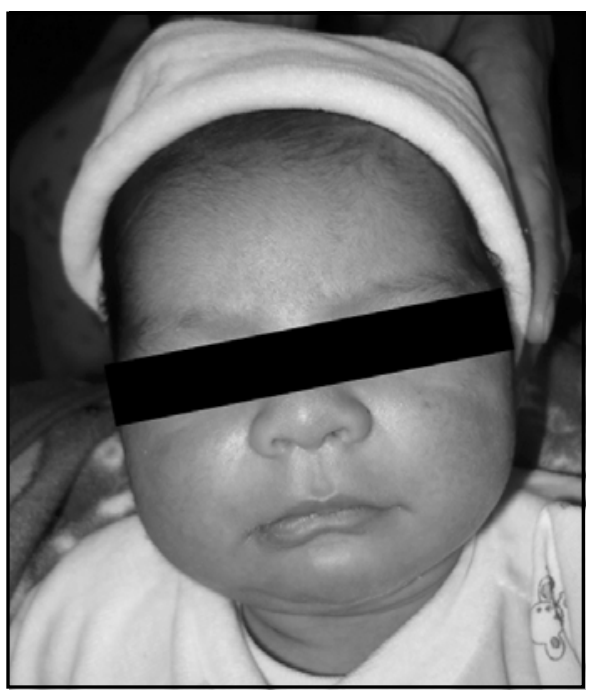

Figura 3. Fotografía del paciente una semana posterior al alta. 


\section{DISCUSIÓN}

La sialoadenitis es la inflamación de las glándulas salivales y es mucho más frecuente en la glándula parótida. Diversos estudios apuntan a que esto se debe a la escasa secreción mucinosa de la parótida en comparación con las otras glándulas salivales mayores ${ }^{4,6,16}$.

La parotiditis supurativa es una enfermedad extremadamente infrecuente en el periodo neonata ${ }^{6,7}$, en un estudio de 9 años se detectaron tan solo 5 casos en 3.624 admisiones hospitalarias $^{8}$. Se han asociado factores como prematurez (hasta $38 \%$ de los pacientes), bajo peso 0 deshidratación $n^{1-3}$. Respecto al género, Spielgel et al publicaron que el $72 \%$ de los casos corresponden a varones ${ }^{1}$.

Los criterios diagnósticos descritos son: aumento de volumen parotídeo con signos inflamatorios, secreción purulenta del conducto de Stenon y crecimiento bacteriano en el cultivo de la secreción parotídea ${ }^{3}$. El paciente descrito presenta todos ellos.

El aumento de volumen en la región parotídea es el signo más prevalente ${ }^{1}$ y la secreción purulenta tras la compresión de la glándula se considera como signo patognomónico de la enfermedad $^{11,12}$.

La presentación unilateral es lo más frecuente ${ }^{1}$. Sin embargo en algunos casos la presentación puede ser bilateral ${ }^{8-10}$.

La infección se adquiere habitualmente por vía ascendente desde la cavidad oral a través del conducto de Stenon ${ }^{5,6,8}$. Sin embargo algunos autores han planteado también la vía hematógena ${ }^{11}$.

La sialectasia desempeña un papel muy importante en la patogenia, ya que aumentaría la susceptibilidad de la glándula a la infección $n^{6}$. En ella confluyen algunos mecanismos etiológicos, como las anomalías estructurales de la glándula parótida, deshidratación, alimentación orogástrica y prematurez.

La deshidratación incluso subclínica aumentaría la viscosidad de la saliva provocando obstrucción parcial del flujo glandular con la consiguiente éstasis ${ }^{13}$.

La alimentación orogástrica prolongada puede llevar a un menor aclaramiento de la saliva causando obstrucción funcional e inflamación local ${ }^{3}$.
La mayor frecuencia en prematuros se ha atribuido al mayor riesgo que éstos presentan de deshidratación ${ }^{4}$.

Otros factores descritos son la septicemia con metástasis en la glándula parótida, los traumatismos orales o la inmunosupresión ${ }^{2-4,13}$. La infección por VIH en el grupo pediátrico puede presentarse únicamente como un aumento de volumen parotídeo asintomático ${ }^{17}$.

Los factores más frecuentemente descritos no se encontraban presentes en el paciente ya que no era prematuro, ni presentó deshidratación y recibió alimentación oral desde el nacimiento. Es por esto que en el estudio del paciente se deberían descartar causas menos evidentes como son las malformaciones del conducto de Stenon 0 la inmunosupresión. Se debería continuar el estudio ambulatorio en otorrinolaringología junto con un estudio inmunológico.

El diagnóstico se basa en hallazgos clínicos y microbiológicos. Las pruebas complementarias ayudan al diagnóstico destacando los exámenes de laboratorio para valorar el compromiso infeccioso del paciente (hemograma, VHS, PCR, perfil bioquímico) y las imágenes (ecografía o TC) ${ }^{2}$.

A pesar de que el recién nacido presentaba buenas condiciones generales, y un foco febril evidente, los neonatos son un grupo de alto riesgo que siempre requiere de hospitalización para el estudio y tratamiento de cualquier patología infecciosa, justificándose la toma de una batería mínima de exámenes de laboratorio (Tabla 1), que ayudan a descartar otros focos infecciosos potencialmente graves. Además, la parotiditis supurativa puede ser causa o consecuencia de una sepsis neonatal, por lo que este signo clínico bastaría para justificar la hospitalización y estudio del recién nacido afectado ${ }^{7}$.

Tabla 1. Exámenes iniciales para estudio de un recién nacido febril
Hemograma/VHS/PCR
Sedimento orina
Urocultivo
Radiografía de tórax
Hemocultivo
Punción lumbar 
Los hallazgos de laboratorio más característicos son la leucocitosis sobre 15.000 con predominio de neutrófilos en $71 \%$ de los casos, reactantes de fase aguda elevados y aumento de amilasemia ${ }^{1}$.

La ecografía generalmente muestra hipoecogenicidad e hipervascularización ${ }^{2,8}$. La tomografía computarizada (TC) podría ser útil para confirmar 0 descartar compromiso extraparotídeo, así como para su diagnóstico diferencial (Tabla 2) $)^{11,14}$.

En este caso el paciente efectivamente presentó leucocitosis de predominio polimorfonuclear, PCR elevada y ecografía concordante, no se le realizó amilasemia ni TC.

El agente más frecuente en la parotiditis supurativa neonatal es el $S$. aureus, lo que concuerda con el caso presentado. Se ha descrito que este agente se encuentra en el $55 \%$ de los pacientes ${ }^{1}$. Otros agentes descritos son los estreptococos Gram positivos, bacilos Gram negativos y aun menos frecuentes gérmenes anaerobios ${ }^{15}$. Tomados en conjunto, los estreptococos Gram positivos

Tabla 2. Diagnóstico diferencial de parotiditis supurativa

Celulitis facial

Abscesos

Adenopatías cervicales o preauriculares

Infección músculo buccinador

Hemangiomas

Linfangioma

Lipomas

Adenomas

Sclerema neonatorium y los bacilos Gram negativos constituyen el $94 \%$ de los agentes causales ${ }^{1}$.

Sin embargo en algunos estudios recientes se ha dado mayor relevancia a los agentes anaerobios como causantes de las parotiditis agudas ${ }^{16}$.

En algunos casos pueden encontrarse parotiditis asépticas ${ }^{13}$. Los agentes descritos se resumen en la Tabla 3.

El tratamiento generalmente consiste en antibióticos endovenosos de inicio empírico con penicilina resistente a penicilinasa (cloxacilina) 0 una cefalosporina hasta obtener los resultados de los cultivos junto con una adecuada hidratación ${ }^{12,15,16}$. De esta forma se manejó al paciente presentado. Otros autores sugieren una combinación de aminoglucócidos y cloxacilina como terapia empírica ${ }^{1,5,7}$.

El pronóstico especialmente en casos producidos por $S$. aureus es favorable ${ }^{13}$, Spiegel et al concluyen que en el $78 \%$ de los casos la terapia antibiótica parenteral es efectiva y el drenaje quirúrgico no resulta necesario ${ }^{1}$.

La mejoría clínica debe ocurrir a las 24-48 horas de tratamiento con reducción del volumen parotídeo, si esto no ocurre, debe considerarse el drenaje quirúrgico ${ }^{1,4}$. En el caso presentado la mejoría clínica se observó a las 24 hrs de tratamiento antibiótico, con disminución del volumen cervical derecho y normalización de la temperatura.

Las complicaciones locales son poco frecuentes, e incluyen parálisis facial, fístula salival, mediastinitis y extensión al canal auditivo externo ${ }^{6}$. La diseminación hematógena y la sepsis es la complicación a distancia más temida ${ }^{7}$.

Tabla 3. Agentes etiológicos en parotiditis supurada neonatal

\begin{tabular}{|ll}
\hline Staphilococos Gram positivos & S. aureus \\
Estreptococos Gram positivos & S. pyogenes \\
& S. agalactiae \\
& S. viridans \\
Bacilos Gram negativos & S. pneumoniae \\
& Escherichia coli \\
& Psedomonas aeruginosa \\
Anaerobios & Klebsiella pneumoniae \\
& Peptoestrestreptococcus intermedius \\
& Prevotella melaninogénica \\
& Prevotella intermedia
\end{tabular}


La parotiditis neonatal a diferencia de los adultos habitualmente cursa sin recurrencias ${ }^{2,3,7,8}$. Sin embargo, si éstas son recurrentes, deben descartarse causas de inmunosupresión, dentro de ellas se ha descrito especialmente al VIH como causante de parotiditis recurrentes a edades pediátricas ${ }^{18,19}$.

\section{BIBLIOGRAFÍA}

1. Spiegel R, Miron D, Sakran W, Horovitz Y. Acute neonatal suppurative parotitis: case reports and review. Pediatr Infect Dis J 2004; 23(1): 76-8.

2. Ayala J, Galán P, Poza C, Aguirre A, Cotero A. Parotiditis Aguda Supurativa Neonatal. An Pediatr (Barc) 2004; 60 (3): 274-7.

3. David RB, O'Connell EJ, Minn R. Suppurative parotitis in children. Am Dis Child 1970; 332-5.

4. Salaria M, Poddar B, Parmar V. Neonatal parotitis. Indian J Pediatr 2001; 68: 283.

5. Templer J, Liess B. Parotitis. Disponible en: http://emedicine.medscape.com/article/ 882461-overview. Consultado el: 07/07/2009.

6. Leake D, Leake R. Neonatal suppurative parotitis. Pediatrics 1970; 46: 202-7.

7. Managol $S$, Chaturvedi P. Suppurative parotitis in a neonate. Indian Pediatr 2002; 39: 407-8.

8. Sabatino G, Verrotti A, De Martino M, Fusillo P, Pallota R, Chiarelli F. Neonatal suppurative parotitis: A study of five cases. Eur J Pediatr 1999; 158: 312-4.

9. Coban A, Ince Z, Ucsel R, Ozgeneci A, Can G. Neonatal suppurative parotitis: A vanishing disease? Eur J Pediatr 1993; 152: 1004-5.

10. Mohyud-Din M, Haider S, Hameed A. Bilateral suppurative parotitis in a newborn. $J$ Coll Physicians Surg Pak 2006; 16(4): 301-2.

11. Fathalla B, Collins D, Ezhuthachan S. Acute suppurative parotitis: Uncommon presentation in a premature infant. J Perinato/2000; 20: 57-9.

12. CHIU CH, LIN TY. Clinical and microbiological analysis of six children with acute suppurative parotitis. Acta Paediatr 1996; 85: 106-8.

13. LINDGREN C, BaLIHODZIC-Lucovic V. Aseptic sialadenitis in preterm infants associated with long-term oro-gastric tube feeding. Eur $J$ Pediatr 1998; 157: 1014-6.

14. Chevalier J, Jadcherla SR. Parotid swelling in a premature neonate. Am J Perinatol 2002; 19: 435-8.

15. Brook I. Suppurative parotitis caused by anaerobic bacteria in newborns. Pediatr Infect Dis J 2002; 21: 81-2.

16. BRook I. Aerobic and anaerobic microbiology of suppurative sialadenitis. J Med Microbiol 2002; 51: 526-9.

17. Al-Maamali Aa, Chacko AP, Javad H, Fathalla M, Shenoy A, Koul R. HIV disease presenting as a unilateral parotid gland swelling. Indian $J$ Pediatr 2008; 75(10): 1087-8.

18. Sculerati N, Borkowsky W. Pediatric human immunodeficiency virus infection: an otolaryngologist's perspective. J Otolaryngol 1990; 19(3): 182-8.

19. PINTo A, De Rossi SS. Salivary gland disease in pediatric HIV patients: an update. J Dent Child (Chic) 2004; 71(1): 33-7.

\author{
Dirección: Dr. Rodrigo Cabezón Alvarado \\ Marcoleta $350,2^{\circ}$ Piso \\ Departamento de Otorrinolaringología, Pontificia Universidad Católica de Chile, Santiago \\ E mail: racabezo@gmail.com
}

